\title{
Managing the diffusion and adoption of renewable energy technologies in Nigeria
}

\author{
Hakeem A. Bada* \\ University of Vaasa, Vaasa, Finland \\ *Corresponding author. Tel: +358445517141,E-mail:hakeem.bada@uwasa.fi
}

\begin{abstract}
Increments in the price of oil in 1970s have brought many countries in search of alternative energy sources which will not cause harm to their entire environment as like fossil fuel does. The only available energy source that is capable of providing perhaps without harm to the environment is renewable energy. Renewable energies are important to an energy supply portfolio as they contribute to the world energy supply security, as well as to reducing dependency on the use of fossil fuel. They also contribute to mitigating greenhouse gases. The diffusion and adoption of a new technology such as renewable energy technologies needs the proper understanding of the environment as well as the existing sources of energy in the area. This paper investigates the current status of energy production and the potential of renewable resources in Nigeria. These investigations were carried out by analyzing the available policies and barriers toward the promotion of using renewable energy technologies in Nigeria. These barriers include political issues, environmental issues, technical issues, as well as economic and social issues.
\end{abstract}

Keywords: Innovation, Renewable energy, Diffusion and adoption.

\section{Introduction}

Nigeria is one of the countries with high potential in energy resources; the country is blessed with both fossil energy resources such as natural gas, coal and crude oil, and renewable energy resources such as biogas, biomass, solar energy and many more.

Energy is claimed to be one of the essential inputs for socio-economic development (BrewHammond, 2010). It is then clear that the connection between energy and the millennium development goals (Parcaco and Takada, 2004) make it more necessary to address the issue of energy problem in Nigeria, most especially electricity generation and distribution (BrewHammond, 2010; Karekezi, and Majoro, 2002; Modi, 2004; Porcaro and Takada, 2004). Therefore, the provision of a constant power supply is the sign of a developed economy. A nation with unstable power supply risks keeps losing potential investors and development (Okoro and Chikuni, 2007). Nigeria is blessed with natural resources; therefore every Nigerian should have access to electricity. For this to materialize there is only one question which needs a quick answer: how can it become reality? The inability of the Power holding of Nigeria to supply Nigerians with adequate electricity has severely affected many sectors of the economy such as manufacturing industries, mining, agricultural production, and households.

This paper will be looking at (1) the current status of energy production in Nigeria, most especially electricity. The policies promulgated by the energy commission of Nigeria will be reviewed, to see which of these policies are in support of the diffusion and adoption of renewable energy in Nigeria. (2) Potential of renewable energy resources in Nigeria will also be reviewed. Nigeria is a country which is blessed with abundant natural resources which includes renewable energy resources such as biomass, solar, biogas, etc. With all these resources in place, Nigerian still depends heavily on the use of fossil fuel for electricity generation. 


\section{Genesis of electricity production in Nigeria}

Electricity generation in Nigeria dates back to 1896, which was the first time of generating electricity in the city of Lagos with a capacity of 60KW. After the first generation, an arm of the then government was established under the jurisdiction of the public works department (PWD) with the responsibility of electricity supply in Lagos. Later, 1950 a central body called the Electricity Corporation of Nigeria (ECN) was established in order to integrate electricity power development and make it more effective (Okoro and Chikuni, 2007).

In complement the work of Electricity Corporation of Nigeria, a new body called Niger Dam Authority (NDA) in charge of dam construction and maintenance, both on the river Niger and in other places within the country. In 1972, both ECN and NDA were merged to become an entity called National Electric Power Authority (NEPA) (Okoro and Chikuni, 2007). The two organizations were merged in the hope that their merger would result in the improvement of production and distribution of electricity power supply throughout the whole country, which would reduce excessive spending on both organizations; and that it would result in the utilization of available resources such as human, financial and other to the electricity supply throughout the country (Okoro and Chikuni, 2007:52).

The above two bodies then metamorphosed into the National Electric Power Authority (NEPA) which then later transformed into the Power Holding Company of Nigeria (PHCN). The Power Sector Reform Bill was signed into law in March 2005 to enable private companies' participation in electricity generation, transmission, and distribution (Okoro and Chikuni, 2007:52). The bill split PHCN into eleven distribution firms, six generating companies, and a transmission company, all of which will be privatized. The bill is yet to become operational due to opposition from the labour unions.

The Energy Commission of Nigeria (ECN) is the only apex government organ empowered to carry out overall energy sector planning and policy implementation, as well as to promote the diversification of energy resources through the development and optimal utilization of all, including the introduction of new and alternative energy resources like solar, wind, biomass and nuclear energy (The Energy Commission of Nigeria, 2010).

\subsection{Position of energy in Nigeria}

Nigeria is an energy rich country as stated above, also rich in human resources with a total population of 140.4 million by the 2006 population census, with an annual population growth rate of about 2.8\% (Akinbami, Ilori, Oyebisi, Akinwunmi, and Adeoti, 2001). Logically, with all of these abundant energy resources, it is expected that Nigerians should have sufficient and sustainable energy, but the reverse is the case. The national energy use trend reveals a dichotomy between urban and rural households, due to the nature of energy forms consumed in Nigeria, specifically commercial energy such as petroleum products, natural gas, coal, and electricity, and non-commercial or traditional energy, like fuelwood and other biomass.

The Manufacturer Association of Nigeria (MAN) claims that about 60 million Nigerians now own power generating sets for their electricity, using generators of varying sizes with diesel as their sources of fuel, which is not environmentally friendly. The same numbers of people spend a staggering N1.56 trillion (\$13.35million) to fuel their generators annually (The Energy Commission of Nigeria, 2010). In his own contribution, Mr. Steven Dimitryer a senior private specialist at the World Bank notes that 'Nigeria experiences the worst electricity crisis among its contemporaries, which underscores the nightmarish generation, distribution and supply in the country' (The Energy Commission of Nigeria, 2010). Electricity is the most 
important infrastructure bottleneck in Nigeria, most of the industries in Nigeria experience power outage and about $85 \%$ of these industries own generators as an alternative source of power generation (ECN, 2010). Presently, about $10 \%$ of rural households and $40 \%$ of the country’s total population have access to electricity in Nigeria (Mbendi.com, 2011).

\section{Renewable energy resources in Nigeria}

With respect to this paper, the renewable energy sources in Nigeria that will be considered are hydropower, solar energy, wind, and biomass energy.

\subsection{Hydropower}

Like every other renewable energy source, hydropower has tremendously contributed to the world energy supplies. The current world capacity of hydropower in 2004 was 2810 TWh and is projected to be 4903 TWh by 2030 with growth of $1.8 \%$ per year, although the share will still remain at $2 \%$ of the world energy supplied (IEA, 2007).

There is high potential for hydroelectricity generation in Nigeria: the current hydropower plants contributed about $29 \%$ of electricity generation to the nation total power supply (Aliu and Elegba, 1990; Sambo, 2005), while all the rest is coming from fossil fuels. The resources for hydroelectricity, unlike other types of renewable energy resources, require only a flow of power over a period of time added up to an annual energy (Boyle, 2004). The availability of rivers and natural falls mean that Nigeria has the potential to provide the needed amount of electricity to revitalize the economy. Total hydropower resources potential exploitable in Nigeria is estimated to be 11,000MW (Sambo, 2005).

\subsection{Small hydropower}

Small hydropower in Nigeria refers to small hydropower generation with a capacity of 1-10 MW. Nigeria is blessed with large rivers along with some natural falls. Nigeria's rivers have the capacity to generate about 11,000 MW of electricity, of which $19 \%$ are currently being developed. Existing hydropower plants in the country need rehabilitation due to lack of adequate maintenance (Aliyu and Elegba, 1990; ECN, 2010). There is no standard definition which size of hydropower is small or large, but Table 1 shows classification of ranges of hydropower along with their capacity.

Table 1. Classification of Hydropower Range (adopted from Aliyu and Elegba,1990) .

\begin{tabular}{cc}
\hline Range of Hydropower & Capacity of Range (MW) \\
\hline Large & $>100$ \\
Medium & $15-100$ \\
Small & $1-15$ \\
Mini & $0.5-1$ \\
Micro & $<.05$ \\
\hline
\end{tabular}

\subsection{Solar energy}

Nigeria is a country with abundant solar resources with an annual average daily sunshine of 6.26 hours, ranging between 3.5 hours along the coastal area and about 9.0 hours on the far northern border (Bala, Ojosu, and Umar, 2000). Approximately 5.08 x $1012 \mathrm{KWh}$ of energy can be received in Nigeria per day from the sun with an efficiency of $5 \%$. This amount of energy is able to produce 2.54 x 106 MWh of electricity from solar energy (Sambo, 2005). Solar energy can be utilized in every part of the country, most especially for rural domestic use and for power supply to remote areas where electricity is still not provided. 


\subsection{Wind energy}

Wind is another free gift to the nation. Its intensity depends on the location of the country. Nigeria is situated within a low to moderate wind zone. Windmills were successfully used in the 1960s, especially in the northern part of Nigeria such as Dundaye village in Sokoto State for pumping water from the borehole. They were also used in Garo, near Kano, for supplying water to notable places such as a school, dispensary and to some houses (Anyanwu and Iwuagwu, 1994). All of these old windmills still exist in their different locations, but they are not working any more due to poor maintenance.

\subsection{Biomass energy}

Resources for biomass in Nigeria can be found in wood, animal waste obtained from agriculture, forestry, municipal and industrial activities and also from aquatic biomass, forage grasses and shrubs. Fuelwood constitutes $37 \%$ of the total energy demand in Nigeria. 95\% of this fuelwood is consumed by households (Energy Commission of Nigeria, 2005). Figure 1 below indicates the share of fuelwood compared with other types of energy sources.

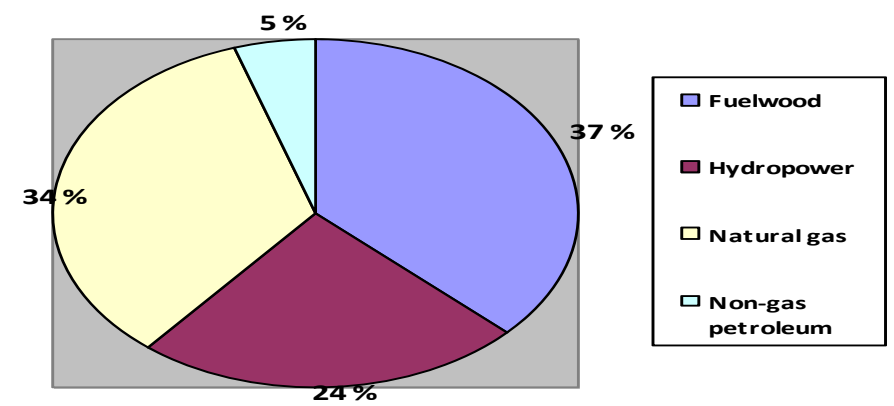

Figure 1. Share of fuelwood compared with other types of energy sources. Data source (ECN, 2005).

\subsubsection{Biogas}

The amount of waste generated in urban areas alone is capable of generating substantial electricity for the populace within the environment. This waste can be transformed into biogas. Biogas is a mixture of about 60 to $70 \%$ methane $\left(\mathrm{CH}_{4}\right), 23$ to $38 \%$ carbon dioxide $\left(\mathrm{CO}_{2}\right)$, about $2 \%$ hydrogen $\left(\mathrm{H}_{2}\right)$ and some traces of hydrogen sulphide $\left(\mathrm{H}_{2} \mathrm{~S}\right)$. Biogas is produced by a process known as anaerobic digestion in the absent of oxygen. This gas can be used in cooking and lighting, as well as for agricultural and industrial production.

The use of biogas is fast spreading all over developing nations, particularly in countries like China, Indian, Taiwan, and Philippines (Akinbami et al., 2001). Biogas production units do exist in the sub-Saharan Africa, with a capacity ranging from less than 100 cubic metres to a larger digester of production capacity of greater than 100 cubic metres (Akinbami, et al., 2001).

The use of biogas is not yet pronounced in Nigeria, but some notable work on it is in progress, which is still at the research stage. The current capacity of digesters in Nigeria ranges between 10-20 cubic metres. These are produced by the Sokoto Energy Research Centre (SERC) and use cow dung, human excreta and piggery waste for biogas production (ECN, 2005; Akinbami, 2001).

\section{Managing renewable energy technology in Nigeria}

The development of a nation's economy is said to be an indication of how well energy is utilized along with the conversion of available energy resources to useful energy technologies 
(Sambo, 2005). In order to ensure optimal, adequate, reliable and secure supply of energy to, and its efficient utilization in the country, it is important to put in place a harmonized, articulate and comprehensive energy policy to support the appropriate energy technologies for the country.

Before now, existing policies in the energy sector have been those of the separate energy subsector, that is, electricity, oil and gas and solid minerals. There have also been energyconnected policies developed in sub-sectors whose activities are strongly dependent on those in the energy sector. These include transportation, agriculture, science and technology and environment, among others. The sub-sectoral policies, however, reflect the individual subsectoral perspectives. ECN, (2003) realized that there is a need to have an integrated energy policy which will guide future energy related sub-sectoral policy developments, in order to avoid policy conflicts which may otherwise arise.

\subsection{Nigeria's energy policy and objectives}

The overall driving force of the energy policy objectives in Nigeria has been the optimal utilization of the nation's energy resources for sustainable development. These policy objectives and implementation have been carefully defined with the notion that energy is crucial to developmental goals and that government has a prime role in meeting the energy challenges facing the nation, most especially the electricity stumbling block. In addition, the nation's dependence on oil can be reduced through the diversification of the nation's other energy sources, aggressive research, development and demonstration (RD \& D), human resources development and many more. Each of the energy sources in Nigeria has its own policy which forms the overall policy of the nation.

\subsection{National Policy position toward the diffusion and adoption of renewable energy in Nigeria}

Stated below are some of the significant elements in national policy toward diffusion and adoption of renewable energy in Nigeria (ECN, 2003).

i. Harnessing hydropower potential available in country for electricity generation, also paying attention to the development of the mini and micro hydropower schemes.

ii. Exploitation of the hydropower resources in an environmentally sustainable manner and encouraging private sectors and indigenous participation in hydropower development.

iii. Promoting the use of alternative energy sources to fuelwood by developing an appropriate technology to use wood chips rather than the direct use of wood.

iv. Aggressive use and integration of solar energy into the nation's energy will be done, by developing the nation's capability in the utilization of solar energy as well as monitoring worldwide development of solar energy technology. To enable the use of solar energy as complementary energy resources in the rural and urban areas.

v. Developing wind energy resources and integrating them with other energy resources to form a balanced energy mix. It will as well involve taking necessary measures to ensure that wind energy is harnessed at a sustainable cost to both suppliers and consumers in the rural areas. 
vi. Developing local capability in wind energy technology and applying it in areas where it is technically and economically feasible.

vii. Harnessing non-fuelwood biomass energy resources and integrating them with other energy resources. Also promoting efficient methods in the use of biomass energy resources.

Increasing the percentage of the contribution of hydro electricity to the total energy mix is yet to be achieved in the country; the survey carried out in harnessing hydropower is yet to be put into effect. Most of the rural areas in the country are still experiencing blackout due to the absence of electricity, while the current hydropower has in one way or the other contributed to ecosystem damage preventing fishermen from getting their daily bread. Furthermore, the maintenance of those available hydro electricity generating plants in the country is far below standard as a result of poor management of the whole system.

About $60 \%$ of Nigeria's population is highly dependent on fuelwood for cooking and other domestic uses. The use of fuelwood arises as a result of lack of appropriate cooking methods. This is not limited to the rural environment alone: even people in the urban area use it as well. It is discerned that the rate of fuelwood consumption far exceeds the replenishing rate, which has resulted in environmental setback. Therefore, the use of innovative ways of cooking is urgently needed both in the rural areas and the urban areas in order to curb the results of global warming.

Rogers, (1995:5) defined diffusion as the process by which an innovation is communicated through certain channels over time among the members of a social system. The rate of diffusion and adoption of renewable energy is very low in Nigeria, as a result of heavy dependence on the use of fossil fuel, since the nation's economy solely depends on the exportation of crude oil and gas. Innovation in the Nigeria energy system needs foreign investors to boost her energy sector: Nigeria's position as one of the lowest consumers of electric power per capita in Africa remains a big issue. Figure 2 shows Nigeria consumption of electric power per capita ranking among some selected countries in Africa.
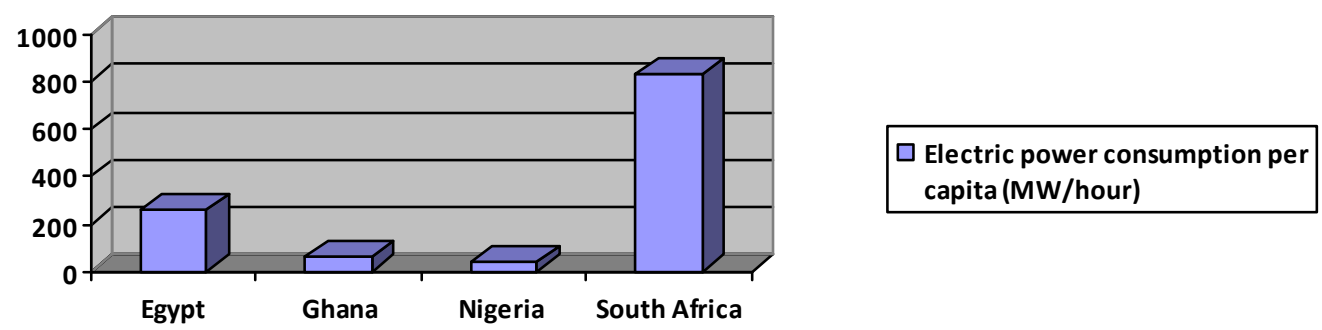

Figure 2. Per capita electric power consumption of some selected countries

\subsection{Barriers to diffusion of renewable energy technologies (RETs)}

Painuly, (2001:75) argues that there are many barriers 'that have prevented penetration of RETs'; some are discuss below.

\subsubsection{Political issues}

First and foremost, there should be stability and transparency in the political environment of Nigeria, with the notion of creating a country of a stable political atmosphere which will attract investors. Complete reform of the current policy on electricity generation and distribution should be overhauled to create a fair way for the whole group of stakeholders in 
the emerging power sectors within and outside Nigeria. Right now, there are some parts of the country which urgently need attention when it comes to investment, such as the Niger Delta area. Establishing viable projects within these areas will not be an easy task, since this region is somehow controlled by the rebels. Other parts of the country with similar political instability issues should be addressed in order to give ways to investors.

\subsubsection{Environmental issues}

When planning for the type of innovation for diffusion and adoption, the government should consider the environmental impacts of the technology before adoption. Also the area where it will be used should be taken into consideration: for example a community with less people should not be allowed to have a gigantic project unless the community is a supply power for other areas. More so, a city with high level of industrial waste should be denied of having similar project to avoid polluting the city together with the inhabitants. Also the use of heavy duty generator fuel with diesel should be discouraged.

\subsubsection{Technical issues}

The worst problems facing most of the power plants in Nigeria at present are technical issues. Inadequate maintenance of existing power plants has led to an insufficient electricity supply. There is a lack of standards, codes, and certification. The educational system of the country is too broad and the curriculums are not tailored to the need of the environment at large.

\subsubsection{Economic and social issues}

It is very appropriate to provide substantial capital for the promotion of renewable energy systems in Nigeria, if the government really wants consumers to have access to electricity that is affordable and available. This capital should have a defined time frame to ensure efficiency improvement in renewable energy technology and the enhancement of the nation's power industries. Therefore, in order to make electricity available to consumer, it will require utilization of the renewable energy resources in the country.

\section{Conclusion}

Energy is as an essential commodity for nation building, Nigerians deserve a constant supply of electricity. This paper has highlighted the genesis of electricity in Nigeria, as well as the potential of renewable energy in the country. It was identified that about N1.56 trillion (\$13.35million) were spent on the fueling of generators as a result of lack of available sustainable electric power to both private and corporate users. Dependence on the use of fossil fuel couple with low per capita consumption of electricity and barriers have a contributed greatly to the low rate of diffusion and adoption of renewable energy technologies in Nigeria

\section{References}

[1] U. O. Aliyu and S. B. Elegba, Prospect for small hydropower development for rural applications in Nigeria. Nigeria Journal of Renewable Energy, 1990, vol.1, pp.74 - 86.

[2] E.E. Anyanwu and C.J. Iwuagwu, Wind Characteristics and Energy Potentials for Owerri, Nigeria. Renewable energy, 1994, vol. 6. No. 2, pp. 125-128.

[3] J-F. K. Akinbami, M. O. Ilori, T. O. Oyebisi,, I. O.Akinwunmi, and O. Adeoti, Biogas Energy Use in Nigeria Current Status, Future Prospect and Policy Implications. Renewable and Sustainable Energy Reviews, 2001, vol. 5, pp.97-112. 
[4] E.J. Bala, O.J. Ojosu and I.H. Umar Government Policy and Programmes on the Deveolopment of Solar-PV Sub-sector in Nigeria, 2000.

[5] G. Boyle, Renewable Energy: power for sustainable future, 2004.

[6] A. Brew-Hammond, Energy access in Africa: Challenges ahead. Energy Policy, 2010, vol.88 pp. 2291-230.

[7] Energy commission of Nigeria, National Energy policy, Federal Government of Nigeria, April 2003.

[8] Energy commission of Nigeria, Renewable Energy Master Plan, 2005, November.

[9] S. Karekezi, and L. Majoro, (2002). Improving modern energy strategies for rural Africa's urban poor. Energy Policy 30 (11-12), 1059-1069.

[10] O.I. Okoro, and E. Chikuni, Power sector reforms in Nigeria: Opportunities and challenges. Journal of Energy Southern Africa, 2007, vol. 18 No 3.

[11] Z. Peidong, Y. Yanli, S. Jin, Z. Yonghong, W. lisheng, and L. Xinrong, Opportunities and challenges for renewable energy policy in China. Renewable and Sustainable Energy Reviews, 2007, 13 pp. 439-449.

[12] J. Porcaco, M. Takada, In: Archiving the Millennium Development Goals: The Role of Energy Services- Case studies from Brazil, Mali and the Philippines, UNDP, 2004, New York.

[13] J.P. Painuly, Barriers to renewable energy penetration; a framework for analysis. Renewable Energy 24 (2001) 73-89.

[14] E.M. Rogers, Diffusion of innovations, The Free Press, NY, Fourth edition, 1995, ISBN 0-02-926671-8.

[15] A.U. Sambo, Renewable Energy for Rural Development: The Nigerian Perspective, ISESCO Science and Technology Vision, 2005, Vol. 1, pp. 12-22.

[16] V. Modi, In: Energy Service for the poor, Commercial paper for the millennium project Task Force 1. Mimeo, Columbia University, 2004, New York.

[17] Mbendi.com, http://www.mbendi.com/indy/powr/af/ng/p0005.htm, 2011. 